\title{
CAN ANGIOTENSIN-CONVERTING ENZYME INHIBITORS INTERFERE WITH THE FREE RADICALS? MEASUREMENT OF ANTIOXIDANT CAPACITY USING DPPH RADICAL REDUCTION EXAMINED BY UV-VIS METHOD
}

\author{
ANNA JUSZCZAK ${ }^{1}$, PAWEŁ RAMOS², WOJCIECH SZCZOŁKO ${ }^{3}$, \\ BARBARA PILAWA ${ }^{2}$ and BEATA J. STANISZ \\ ${ }^{1}$ Chair and Department of Pharmaceutical Chemistry, \\ Poznan University of Medical Sciences, Poland \\ ${ }^{2}$ Department of Biophysics, School of Pharmacy and Laboratory Medicine, \\ Medical University of Silesia in Katowice, Poland \\ ${ }^{3}$ Chair and Department of Chemical Technology of Drugs, \\ Poznan University of Medical Sciences, Poland
}

\begin{abstract}
A negative impact of radicals on human's health is responsible for growing research interest in antioxidant properties of substances, which protect organisms from the damaging influence of these reactive species. Angiotensin-converting enzyme inhibitors (ACE-I) are the most popular drugs used in cardiovascular diseases. There are a lot of clinical reports that ACE-I have antioxidant properties, due to the fact, that prolonged use improves conditions of patients with neurodegenerative disorders and slow inflammatory processes. The paper shows the antioxidant properties of a selected ACE-I: cilazapril, ramipril, imidapril, lisinopril, perindopril, and quinapril. Among numerous methods for antioxidant activity estimation, DPPH reduction is the most popular and commonly used one due to its ease, speed, sensitivity and the usage of stable radicals. UVVis spectrophotometry was used to examine interactions of chosen ACE-I with model-free radicals. Absorption of UV-Vis spectra of DPPH (reference), and DPPH interacting with the tested ACE-I were compared. For all tested ACE-I kinetics of their interaction with DPPH, up to $30 \mathrm{~min}$, were obtained. The strongest interaction with DPPH was observed for imidapril and cilazapril and the lowest interaction for lisinopril. Studies have shown usefulness UV-Vis spectrophotometry for obtaining information on interactions of ACE-I with modelfree radicals.
\end{abstract}

Keywords: free radicals, antioxidant, UV-Vis spectrophotometry, angiotensin-converting enzyme inhibitors (ACE-I)

The physiological role of the renin-angiotensin system (RAS) is the maintenance of correct blood pressure. The angiotensin-I converting enzyme (ACE) is a crucial component of this system, and it is responsible for the conversion of angiotensin I to angiotensin II (1-2). When the system is inefficient, and the balance between angiotensin I and angiotensin II is not preserved, this regulation can be maintained by angiotensin-converting enzyme inhibitors (ACE-I). This well-known group of drugs is widely prescribed as antihypertensive agents. What is more, in the clinical trials ACE-I are also reported as very beneficial for patients with comorbidities, and the positive effects can be found beyond the circulatory system. (3-5). A feature connecting pleiotropic activity of this group of drugs is the fact that the positive influence can be associated with inhibition of reactive oxygen species (ROS) and inflammation processes. Angiotensin II can trigger ROS production by activation of NADPH oxidase, which can be related to atherosclerosis $(6,7)$. Clinical trials have shown that patients taking ACEI have a lower level of inflammatory markers, what is helpful in the treatment of rheumatoid arthritis (8), hepatitis (9), nephropathy (10) and retinopathy (11). ROS, which can also be produced in substantia nigra and striatum in the brain, are immensely toxic, especially for the dopaminergic neurons. Those ACE-I

* Corresponding author: e-mail: anna.juszczak28@gmail.com 
that are active in the central nervous system protects cells from damage and may become an alternative for treatment of Parkinson's disease $(12,13)$. Likewise, there is a significant correlation between brain RAS system, production of free radicals, inflammatory process and Alzheimer's disease. Due to long-term trials, among all the patients taking different antihypertensive drugs, only the group receiving ACE-I (penetrating the blood-brain barrier) had a considerably lower risk of dementia and Alzheimer's disease $(14,15)$.

As all the reports about antioxidant properties of ACE-I described above, come from clinical investigations or animals models, the aim of the study was to determine antioxidant capacity of ACE-I in vitro - using DPPH (2,2-diphenyl-1-picrylhydrazyl) free-radical model. This method is based on DPPH reduction reaction, which can be examined by UVVis spectrophotometry.

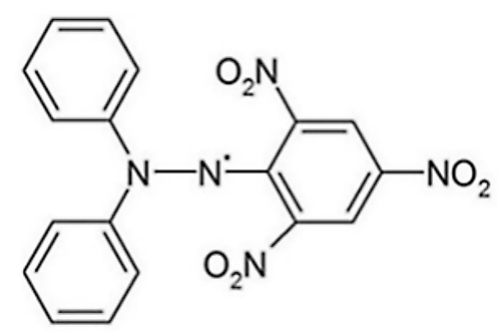

Figure 1. Chemical structure of DPPH (2,2-diphenyl-1-picrylhydrazyl) molecule. $(\bullet)$ - unpaired electron (16-18)
The method was used before on other groups of drugs (16-20), therefore, in this study, it has been applied to test the antioxidant properties of ACE-I.

\section{EXPERIMENTAL}

\section{Method}

Chemical structure of DPPH and localization of unpaired electrons is shown in Figure 1. DPPH was purchased from the Sigma-Aldrich company.

DPPH was used as ethyl alcohol solution $(0.5$ $\mathrm{mM})$. DPPH powder $(394.32 \mathrm{~g} / \mathrm{mol})$ was dissolved $19.71 \mathrm{mg}$ in $100 \mathrm{~cm}^{3}$ ethyl alcohol, and the maximum of absorbance is at $517 \mathrm{~nm}$. The obtained solution was diluted so that its absorbance at wavelength $\lambda=517 \mathrm{~nm}$ was about 1.3. Spectra of DPPH in ethyl alcohol are presented in Figure 2.

\section{Samples characterization}

Tested ACE-I were: cilazapril (supplied by Biofarm), ramipril (supplied by Sanofi-Aventis), imidapril (supplied by Jelfa Pharmaceuticals), lisinopril (supplied by FarmSpania), perindopril (supplied by Bachem), and quinapril (supplied by Biofarm) - Table 1.

\section{Chemicals}

In experiment $50 \mathrm{mg}$ ACE-I was mixed with $1.5 \mathrm{~mL} 0.5 \mathrm{mM}$ DPPH in ethyl alcohol solution. Measurements change absorbance $(517 \mathrm{~nm})$ for ACE-I interaction with DPPH. Absorbance was measured at room temperature after 1, 3, 6, 9, 12, 15 and 30 min interaction ACE-I with DPPH, due to the previously described method. Three repetitions of each measurement were carried out. Calibration was
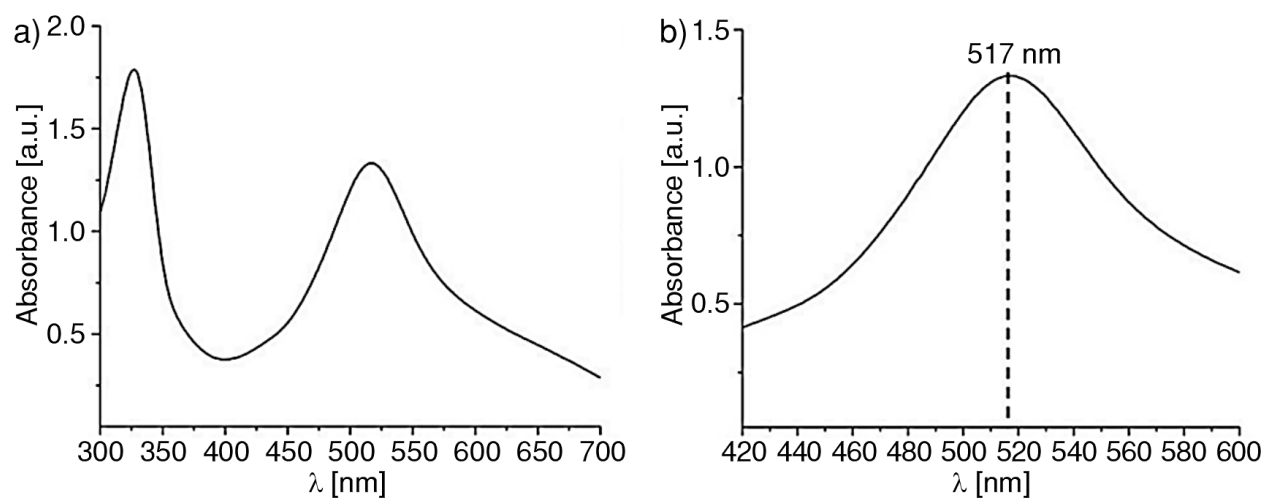

Figure 2. Absorption spectra UV-Vis of DPPH in ethyl alcohol are presented; (a) wavelength from $300 \mathrm{~nm}$ to $700 \mathrm{~nm}$, (b) wavelength from $420 \mathrm{~nm}$ to $600 \mathrm{~nm}$ - the maximum of absorption is marked $(517 \mathrm{~nm})$ 
Table 1. Physical and pharmacokinetic properties of selected ACE-I: $\mathrm{t}_{\max }$ - time to reach peak serum concentration, $\mathrm{c}_{\max }-$ maximum serum concentration, $\mathrm{f}_{\mathrm{b}}$ - protein binding, F- bioavailability, BBB - penetrating the blood-brain $(1,4,21)$.

\begin{tabular}{|c|c|c|c|c|c|c|c|c|}
\hline $\begin{array}{l}\text { ACE-I/ its } \\
\text { active form }\end{array}$ & Structure & $\mathrm{t}_{\max }[\mathrm{h}]$ & $\log P^{*}$ & $\begin{array}{c}\mathrm{IC}_{50} \\
{[\mathrm{nM}]}\end{array}$ & $\mathrm{c}_{\max }[\mathrm{ng} / \mathrm{L}]$ & $\mathrm{f}_{\mathrm{b}}[\%]$ & $\mathrm{F}[\%]$ & $\mathrm{BBB}$ \\
\hline $\begin{array}{l}\text { Imidapril/ } \\
\text { Imidaprilat }\end{array}$ & & 2 & -0.23 & 1.7 & 34.7 & 85 & 70 & No \\
\hline Lisinopril & & 7 & -3.1 & 1.2 & 38 & 10 & 25 & Yes \\
\hline $\begin{array}{l}\text { Perindopril// } \\
\text { Perindoprilat }\end{array}$ & & 2 & 0.63 & 1.5 & 116 & $10-20$ & 66 & Yes \\
\hline $\begin{array}{c}\text { Quinapril/ } \\
\text { Quinalaprilat }\end{array}$ & & 0.63 & 1.96 & 2.8 & 579 & 97 & 37 & No \\
\hline $\begin{array}{l}\text { Ramipril/ } \\
\text { Ramiprilat }\end{array}$ & & 0.7 & 1.47 & 2.0 & 52.2 & 73 & 28 & No \\
\hline $\begin{array}{l}\text { Cilazapril/ } \\
\text { Cilazaprilat }\end{array}$ & & 0.83 & -1.01 & 1.9 & 81.8 & 30 & 77.5 & Yes \\
\hline
\end{tabular}


carried out in $96^{\circ}$ ethanol. Recorded spectra of absorbance range $420-600 \mathrm{~nm}$ by the used UV-Vis spectrophotometer Genesys $10 \mathrm{~S}$ (Thermo Scientific Company, Massachusets, USA). UV-Vis measurements were performed using spectroscopic program VISIONlite (Thermo Scientific Company, Massachusets, USA). UV-Vis analysis was performed using a program Origin 2016 (OriginLab Company, Illinois, USA).

\section{Statistical analysis}

The results are the arithmetic mean of three measurements for each sample. The statistics were made using the STATISTICA software Statsoft company (Poland). The analysis of variance
(ANOVA) was used. The significance level was assumed $\mathrm{p} \leq 0.05$.

\section{RESULTS AND DISCUSSION}

Interactions of ACE-I with model-free radicals (DPPH) were measured by UV-Vis spectrophotometry. The method confirmed the antioxidant properties of tested angiotensin-converting enzyme inhibitors.

UV-Vis absorption spectra of DPPH in ethyl alcohol solution were quenched at the wavelength of $517 \mathrm{~nm}$. The quenching of UV-Vis absorption spectra of DPPH by ACE-I is shown in Figure 3. UV-Vis absorption spectra of DPPH (Fig. 3a-f) interacting
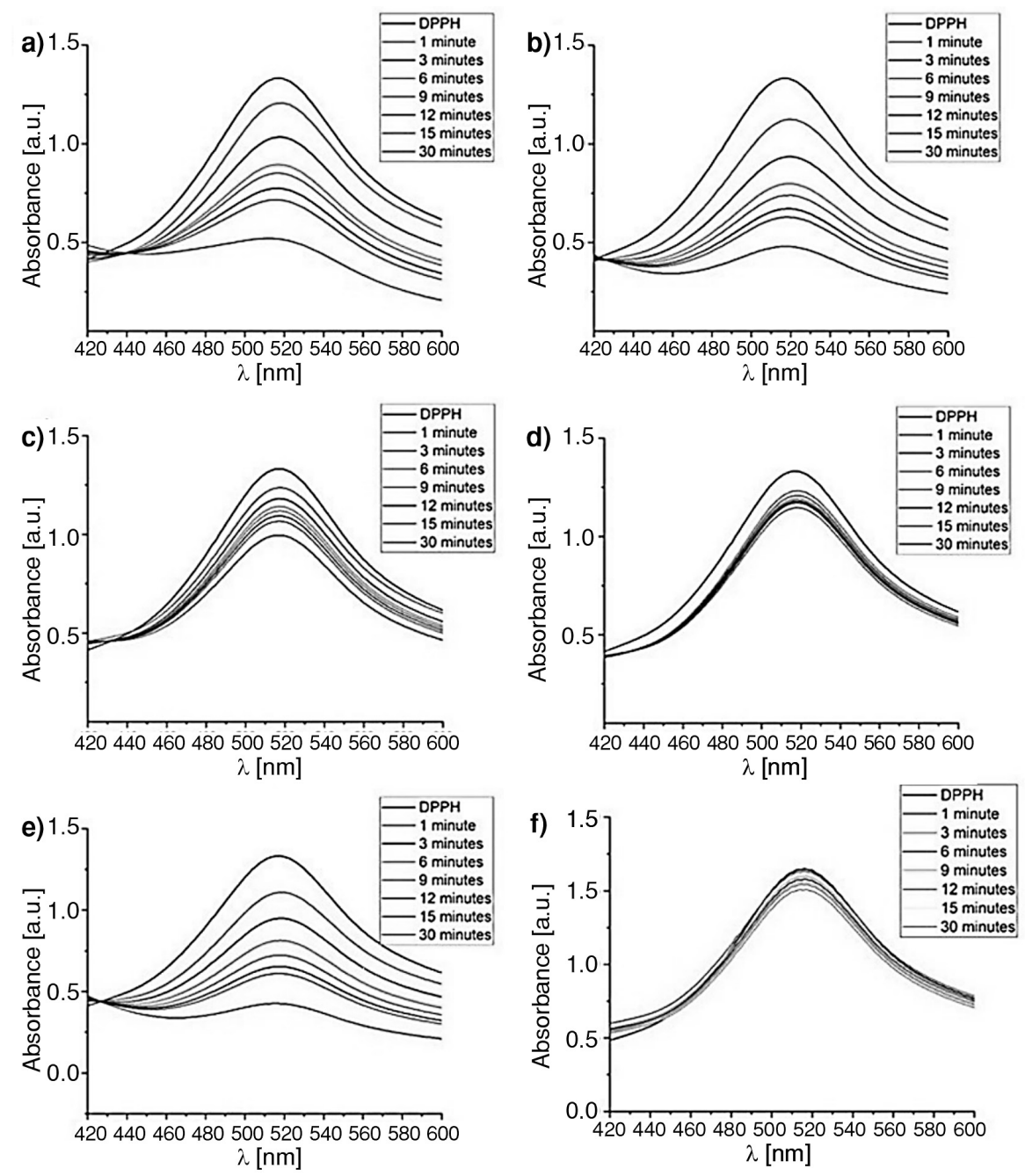

Figure 3. UV-Vis absorption spectra of DPPH interacting with (a) cilazapril, (b) imidapril, (c) perindopril, (d) ramipril, (e) quinapril, and (f) lisinopril during 1, 3, 6, 9, 12, 15, and $30 \mathrm{~min}$. Wavelength $420-600 \mathrm{~nm}$. Maximum of absorption 517 [nm] 


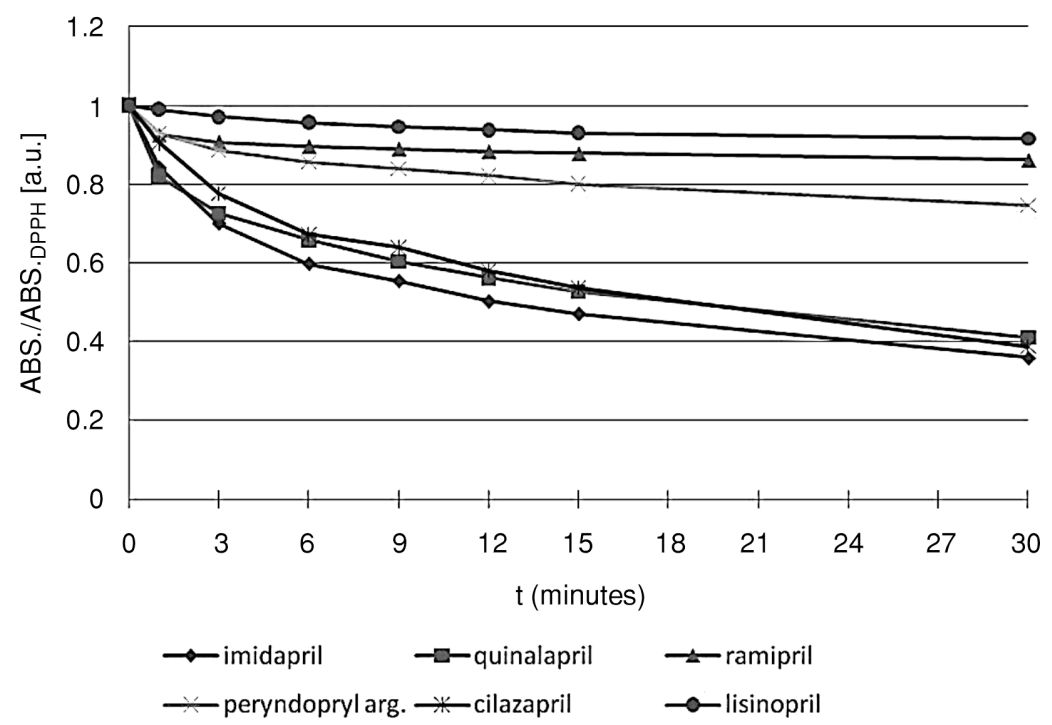

Figure 4. Changes of absorption of UV-Vis spectra of DPPH interacting with ACE-I with increasing interaction time (t)

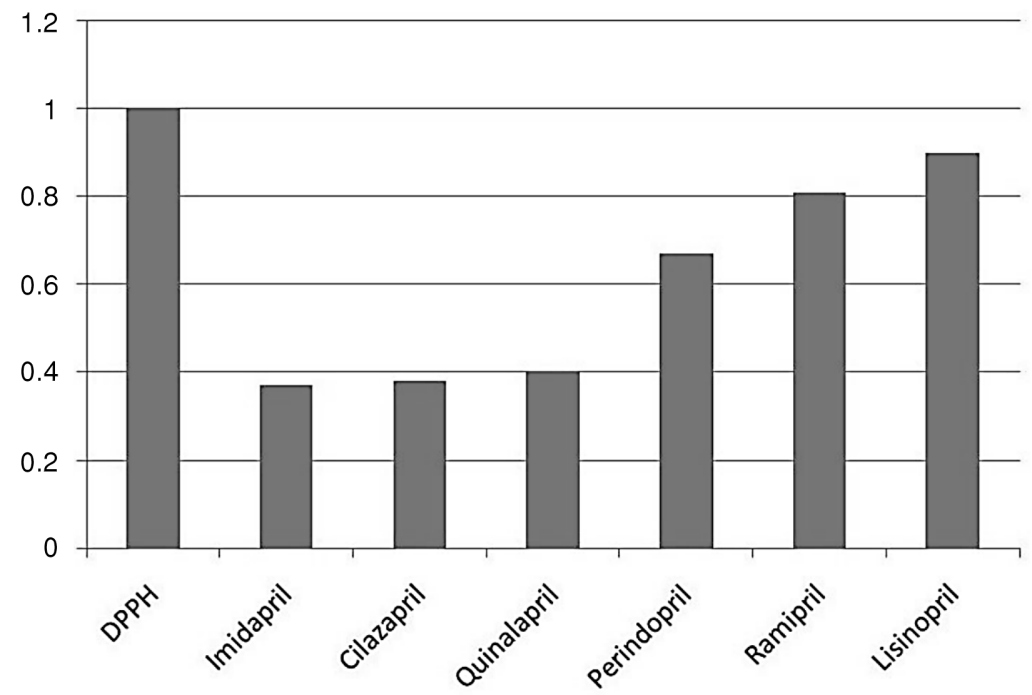

Figure 5. Comparison of the absorption of UV-Vis spectra of DPPH interacting with the tested ACE-I after 30 min of the incubation

Table 2. Calculated \% inhibition for ACE-I after $30 \mathrm{~min}$ incubation. For comparison, the L-ascorbic acid test.

\begin{tabular}{|c|c|c|c|c|c|c|c|}
\hline Test sample & L-acorbic acid* & Imidapril & Cilazapril & Perindopril & Ramipril & Quinalapril & Lisinopril \\
\hline$\%$ inhibition & 100 & 61.8 & 61.2 & 58.9 & 25.3 & 13.9 & 8.4 \\
\hline
\end{tabular}


with the tested ACE-I during 1, 3, 9, 12, 15, and 30 min are compared.

The kinetics of quenching at the wavelength of $\mathrm{UV}-\mathrm{Vis}$ absorption spectra of DPPH by examined ACE-I are presented in Figure 4. Absorption spectra of DPPH decreased with increasing the time of interaction with ACE-I.

The tested angiotensin-converting enzyme inhibitors differed in scavenging activity of the model-free radical (DPPH). Absorption of UV-Vis spectra of DPPH proved that the interactions of the tested ACE-I with DPPH decreased in the fooling order: imidapril $>$ cilazapril $>$ quinapril $>$ perindopril $>$ ramipril $>$ lisinopril - Figure 5 .

For the all tested ACE-I \% inhibition parameters were compared. The $\%$ of inhibition increases with the improvement of antioxidant properties. The $\%$ inhibition was calculated using the formula (22):

$\%$ inh. $=$ Abs. $_{\text {DPPH }}-$ Abs. $_{\text {samp. }_{\text {. }} / \text { Abs }_{\text {DPPH }}} \times 100$

Where: Abs. DPPH $_{\text {- the }}$ absorbance of the standard alcoholic DPPH solution ( $c=0.5 \mathrm{mM})$, Abs. $_{\text {samp. }}$ the absorbance of the standard alcohol DPPH solution interacting with the tested ACE-I at the $30^{\text {th }} \mathrm{min}$ of the measurement.

The tested angiotensin-converting enzyme inhibitors differ in \% inhibition activity of the model-free radical (DPPH), the results are shown in Table 2.

\section{CONCLUSIONS}

Hypertension is one of the most common diseases all over the world, and as antihypertensive drugs are the most frequently prescribed group of medicines, it should be taken into consideration that using ACE-I has many advantages besides hypertension treatment, especially for patients in advanced age and with comorbidities. Their beneficial actions such as cardioprotection, vasoprotection, renoprotection or cerebroprotection represent a high added value to their primary hypotensive effect, thanks to which they finally became the key to the neurohormonal treatment of cardiac insufficiency. Furthermore, the continually increasing understanding of the biophysical and pharmacological features can still provide new opportunities for extending their already broad clinical application. UV-Vis examination of ACE-I indicated that:

- All tested drugs have antioxidant properties. Tested ACE-I quenched absorption UV-Vis of DPPH.

- Imidapril and cilazapril have the strongest interaction with DPPH and lisinopril has the weakest interaction with DPPH confirmed.
- The kinetic studies indicated that the ACE-I differed in the speed of interaction with DPPH.

- The tested ACEI-I can decrease free radical generation during cardiovascular disease.

- UV-Vis method may be useful to characterize the interactions of ACE-I with free radicals.

Results of such trials can show that ACE-I can give long-term benefits to patients besides its antihypertensive effects.

\section{Competing interests}

The authors declare that they have no competing interests.

\section{Acknowledgments}

This work was financially supported by the University of Medical Science in Poznan, grant number: 502-01-03305411-05995 and by the Medical University of Silesia in Katowice.

\section{REFERENCES}

1. Regulska K., Stanisz B., Regulski M., Murias M.: Drug Discov. Today 19, 1731 (2014).

2. Sica D.A.: Curr. Hypertens. Rep. 12, 67 (2010).

3. Daly C.A., Fox K.M., Remme W.J., Bertrand M.E., Ferrari R., Simoons M.L.: Eur. Heart J. 26, 1369 (2005).

4. Wzgarda A., Kleszcz R., Prokop M., Regulska R., Regulski M. et al.: Eur. J. Pharmacol. 797, 9 (2017).

5. George A.J., Thomas W.G., Hannan R.D.: Nat. Rev. Cancer. 10, 745 (2010).

6. Husain K., Hernandez W., Ansari R.A., Ferder. L.: World J. Biol. Chem. 6, 209 (2015).

7. Husain K., Suarez E., Isidro A., Ferder L.: Am. J. Nephrol. 32, 296 (2010).

8. Wahba M.G., Shehata-Messiha B.A., Abo-Saif AA.: Eur. J. Pharmacol. 765, 307 (2015).

9. Reza H.M., Tabassum N., Sagor M.A., Chowdhury M.R., Rahman M. et al.: Toxicol. Mech. Methods 26, 46 (2016).

10. Alderson N.L., Chachich M.E., Frizzell N., Canning P., Metz T.O. et al: Diabetologia 47, 1385 (2004).

11. Zheng Z., Chen H., Ke G., Fan Y., Zou H. et al.: Diabetes 58, 954 (2009).

12. Muñoz A., Rey P., Guerra M.J., MendezAlvarez E., Soto-Otero R., Labandeira-Garcia J.L.: Neuropharmacology 51, 112 (2006).

13. Wright J.W., Harding J.W.: Parkinsons Dis. 2012, 860923 (2012). 
14. Ohrui T., Tomita N., Sato-Nakagawa T.: Neurology 63, 1324 (2004).

16. Dong Y.F., Kataoka K., Tokutomi Y., Nako H., Nakamura T. et al.: FASEB J. 25, 2911 (2011).

17. Bartosz G.: The second face of oxygen, PWN, Warsaw 2012 (in Polish).

18. Bondet V., Brand-Williams W., Berset C.: LWT - Food Sci. Technol. 30, 609 (1997).

19. Tirzitis G., Bartosz G.: Acta Biochim. Pol.: 57, 139 (2010).
20. Momen M., Haghi B., Morsali A., Ardalan P., Ardalan T.: JCHR 2, 43 (2012).

21. Shekar T.C., Anju G.: Am. J. Ethnomedicine 1, 244 (2014).

22. Regulski M., Regulska K., Stanisz B.J., Murias M., Gieremek P. et al.: Curr. Pharm. Des. 21, 1764 (2015).

23. Rice-Evans C., Miller N.J., Paganga G.: Free Rad. Biol. Med. 20, 933 (1996).

Received: 13.06. 2018 